\title{
Primulina dongguanica F. Wen, Y. G. Wei \& R. Q. Luo (Gesneriaceae), a new species from South China
}

\author{
Fang Wen \& Yi-Gang Wei
}

\begin{abstract}
WEN, F. \& Y.-G. WEI (2014). Primulina dongguanica F. Wen, Y. G. Wei \& R. Q. Luo (Gesneriaceae), a new species from South China. Candollea 69: 9-19. In English, English and French abstracts.

A new species, Primulina dongguanica F. Wen, Y. G. Wei \& R. Q. Luo (Gesneriaceae) is described and illustrated from Dongguan city, Guangdong province, S China. The species grows in crevices of granite within subtropical evergreen broad-leaved forests or shrubby vegetation in the Yinpingzui nature reserve. Primulina dongguanica differs from other species in the genus occurring in Guangdong province, China. Despite sharing some morphologically characters with Primulina eburnea (Hance) Y. Z. Wang, Primulina dryas (Dunn) Mich. Möller \& A. Weber, Primulina napoensis (Z. Y. Li) Mich. Möller \& A. Weber and Primulina spec. nov., several features allow its recognition. It is an endemic species confined to the Yinpingzui nature reserve. Its conservation status is also presented.
\end{abstract}

\section{Key-words}

GESNERIACEAE - Primulina - China - Taxonomy

\section{Résumé}

WEN, F. \& Y.-G. WIE (2014). Primulina dongguanica F. Wen, Y. G. Wei \& R. Q. Luo (Gesneriaceae), une nouvelle espèce du Sud de la Chine. Candollea 69: 9-19. En anglais, résumés anglais et français.

Une nouvelle espèce, Primulina dongguanica F. Wen, Y. G. Wei \& R. Q. Luo (Gesneriaceae) est décrite et illustrée de la ville de Dongguan de la province de Guangdong en Chine du Sud. Cette espèce pousse dans les crevasses de granite, dans la forêt de feuillus subtropicale sempervirente ou dans la végétation buissonnante de la réserve naturelle de Yinpingzui. Primulina dongguanica diffère des espèces du même genre qui sont répertoriées pour la province du Guangdong en Chine. Quoique morphologiquement proche de Primulina eburnea (Hance) Y. Z. Wang, Primulina dryas (Dunn) Mich. Möller \& A. Weber, Primulina napoensis (Z. Y. Li) Mich. Möller \& A. Weber et Primulina spec. nov., elle s'en distingue au travers de plusieurs caractères distinctifs. C'est une espèce endémique de la réserve naturelle de Yinpingzui. Son statut de conservation est présenté.

Addresses of the authors: Guangxi Key Laboratory of Functional Phytochemicals Research, Guilin Botanic Garden, Guangxi / Institute of Botany, Yanshan District, Guilin, CN-541006, Guangxi, China. Email (FW): wenfang760608@139.com 


\section{Introduction}

Until recently, Chirita D. Don (Don, 1822) was one of the largest genera of Asian Gesneriaceae, consisting of over 150 species (LI \& MöLler, 2009), with a distribution in South China, Indo-China Peninsula, Malay Peninsula, Indonesia, Nepal, Burma, Bhutan, India (Wood, 1974; Li \& WANG, 2004). The genus had been classified into four sections, sect. Chirita D. Don, sect. Microchirita Clarke, sect. Gibbosaccus Clarke and sect. Liebigia (Endl.) C. B. Clarke (Wood, 1974; WANG, 1981; WANG \& al., 1990, 1998; HilliarD, 2004; Li \& WANG, 2004). Based on molecular evidence (LI \& WANG, 2007; MöLLER \& al., 2009, 2011), all species of the previous Chirita sect. Gibbosaccus, all species of the genus Chiritopsis W. T. Wang (WANG, 1981), and two species of Wentsaiboea D. Fang \& D. H. Qin, W. renifolia D. Fang \& D. H. Qin (LI \& WANG, 2004) and $W$. luochengensis Yan Liu \& W. B. Xu (LIU $\&$ al., 2010), were formally merged into the previously monotypic genus Primulina Hance, to include more than 130 species (WEBER \& al., 2011; WANG \& al., 2011).

Ru-Quan Luo, found a population of Primulina-like plants in Dongguan city, Guangdong in 2009 (Luo, pers. comm.). He collected specimens, took photographs and sent this material to us for identification. After consulting the relevant literature (e.g. WANG \& al., 1990, 1998; LI \& WANG, 2004; WeI \& al., 2010; Li \& al., 2012; Wen \& al., 2012a, 2012b, 2012c, 2012d) and herbarium specimens from CDBI, IBK, PE, KUN, IBSC, HITBC, HIB, HN, VNM, we found the newly collected plants to be similar to a widespread species, P. eburnea (Hance) Y. Z. Wang and other three endemic ones, P. dryas (Dunn) Mich. Möller \& A. Weber, P. napoensis (Z. Y. Li) Mich. Möller $\&$ A. Weber and a new species not yet described, $P$. spec. nov. However we can easily distinguish them by several characters, and the newly collected plant is described as a new species, illustrated here, and its conservation status and geographical origin presented. The plant is included, with photographs, in WEI \& al. (2010).

\section{Material and methods}

This study is based on research in the field, and measurements of both fresh and dried specimens were gathered. Material of the new species was examined under an Olympus CX41 microscope with $4-100 \times$ Oil magnifications (Tokyo, Japan).

\section{Results}

Primulina dongguanica F. Wen, Y. G. Wei \& R. Q. Luo, spec. nova (Fig. 1-2).

Typus: ChINA. Guangdong: Yinpingzui nature reserve in Dongguan city, grows in crevices of granite cliffs under subtropical evergreen broad-leaved forests and shrubs, ca. 276 m, 22 ${ }^{\circ} 53^{\prime}$ N, 114 ${ }^{\circ} 14^{\prime}$ E, 3.VIII.2009, Fang Wen 100803 (holo-: IBK!; iso-: IBK!).

A Primulina eburnea, P. dryas, P. napoensis et P. spec. nov. differt bractis rhombiformis, sub angulo ca. $45^{\circ}$ abientibus, calyx lobis late lanceolatis, corolla $4.5-5.5 \mathrm{~cm}$ longa, filamentis ca. $20 \mathrm{~mm}$ longis, pistillo $3.5-4.2 \mathrm{~cm}$ longo, dense villoso, eglandulato.

Perennial herbs. Short somewhat succulent stems, 1-1.5 cm long, 1.1-1.2 cm in diameter, internodes indistinct. Leaves 6-10, basal or in whorls of three arranged at the top of stem; leaf lamina fleshly chartaceous, ovate-elliptic, 7-15 $\times$ 6-10.5 cm, base slightly oblique or symmetrical, broadly cuneate to cordate, margin irregularly obtuse-serrate, apex acute, sparsely strigose on both sides, 3-4-nerved on each side; petiole compressed, 2.5-6.5 $\times 0.7-1 \mathrm{~cm}$, pubescent and sparsely strigose. Cymes axillary, 3-5 or more, 3-5-flowered or more; peduncle $10.5-16 \mathrm{~cm}$ long, $1.7-2.3 \mathrm{~mm}$ in diameter, densely erectly long pubescent; bracts 2 , opposite, rhombic, 2.1-4.5 $\times$ $1.2-1.6 \mathrm{~cm}$, pubescent outside, nearly glabrous inside, positioned at ca. $45^{\circ}$ angle, margin entire, apex acute; pedicel 8 $17.5 \mathrm{~mm}$ long, densely long pubescent. Pedicel $1.2-2.2 \mathrm{~cm}$, puberulent and glandular puberulent. Calyx 5-parted to the base, lobes equal, broadly lanceolate, ca. $5 \times 1.8-2.2 \mathrm{~mm}$, pubescent outside, nearly glabrous inside. Corolla $4.5-5.5 \mathrm{~cm}$ long, orifice 9-1.1 mm in diameter, purple, lilac or fuchsia, the colour of the throat pale purple with two yellowish brown stripes, tubular, the upper part of the interior of the corolla with two dark brown stripes; interior yellowish brown, tube swollen, outer side densely erect-pubescent, inner glabrous; limb distinctly 2-lipped, adaxial lip 2-parted to the middle, lobe ca. $1 \mathrm{~cm}$ long, triangular; abaxial lip 3-parted to the base, lobes oblong, 1.2-1.3 cm long. Stamens 2, adnate to ca. $2.3 \mathrm{~cm}$ above the corolla base; anthers reniform, ca. $5 \mathrm{~mm}$ long, slightly constricted at the middle, glabrous; filaments ca. $2 \mathrm{~cm}$ long, pubescent, geniculate at the middle; staminodes 2 with broad base, gradually narrowed to apex, curved in upper part, apex capitate, 8-9 mm long, glabrous; disc annular, brown, ca. $1 \mathrm{~mm}$ high. Pistil 3.5-4.2 cm long, densely pubescent, eglandular; ovary linear; style 4-5 mm long. Stigma 2-lobed, 2.5-3 mm long. Capsule and seeds not seen.

Etymology. - The specific epithet is derived from the type locality, Dongguan City, Guangdong.

Phenology. - Flowering in August. 


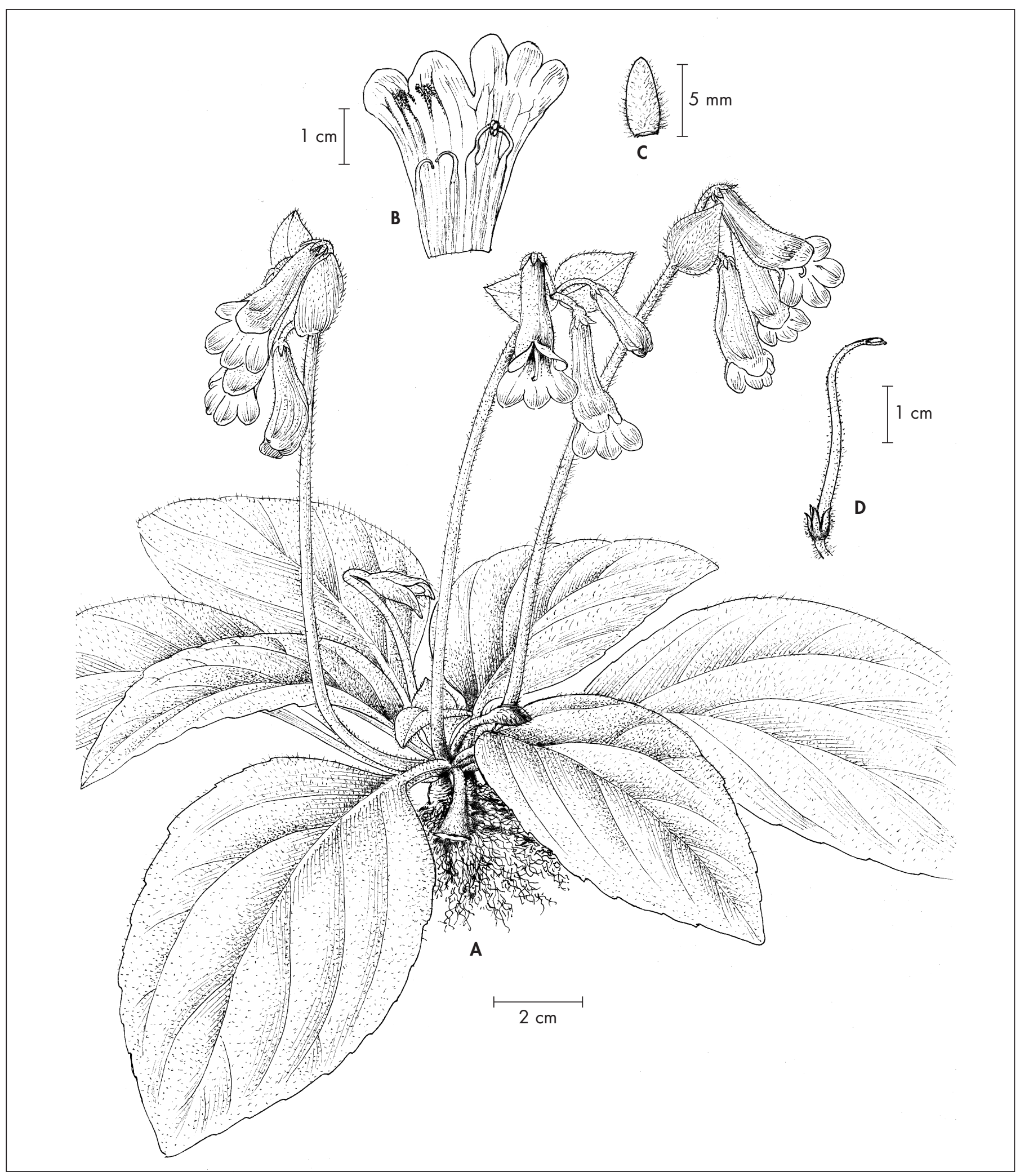

Fig. 1. - Primulina dongguanica F. Wen, Y. G. Wei \& R. Q. Luo. A. Habit; B. Opened corolla with stamens and staminodes; C. One calyx lobe; D. Calyx and pistil. [Fang Wen 100803, IBK] [Drawing: Wen-Hong Lin] 


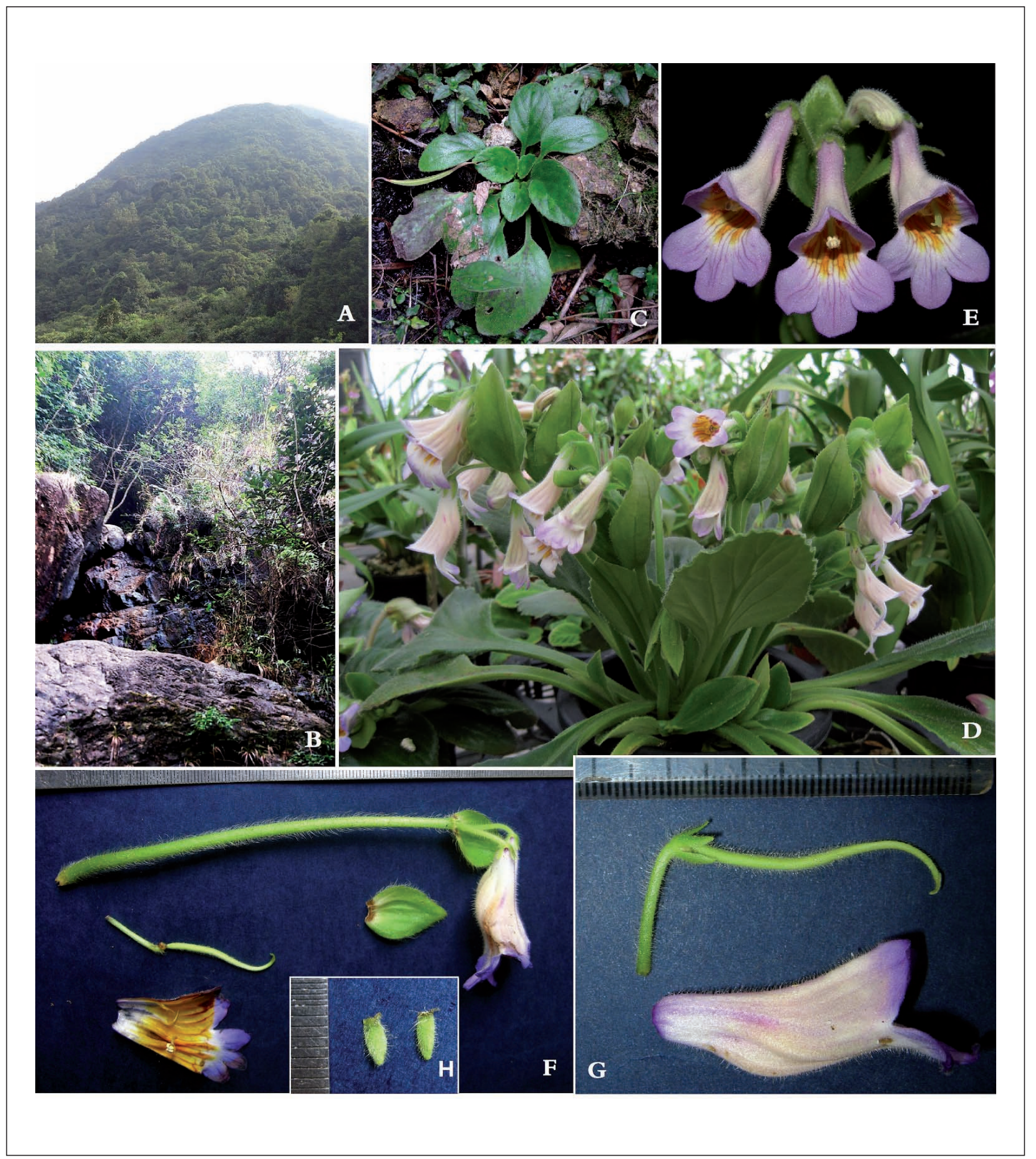

Fig. 2. - Primulina dongguanica F. Wen, Y. G. Wei \& R. Q. Luo. A. Natural hillside habitat; B. Natural habitat; C. Plant in natural habitat; D. Plant with cymes and flowers in cultivation; E. Frontal view of cyme and flowers; F. Anatomical dissections of the cyme, showing bracts, pistil and opened corolla; G. Lateral view of flower, calyx and pistil; H. Adaxial and abaxial views of calyx lobes.

[D-H: Fang Wen 100803, IBK] [Photos: A-C: Fang Wen; D-E: Shi-Liang Mo; F-H: Wen-Hong Lin] 


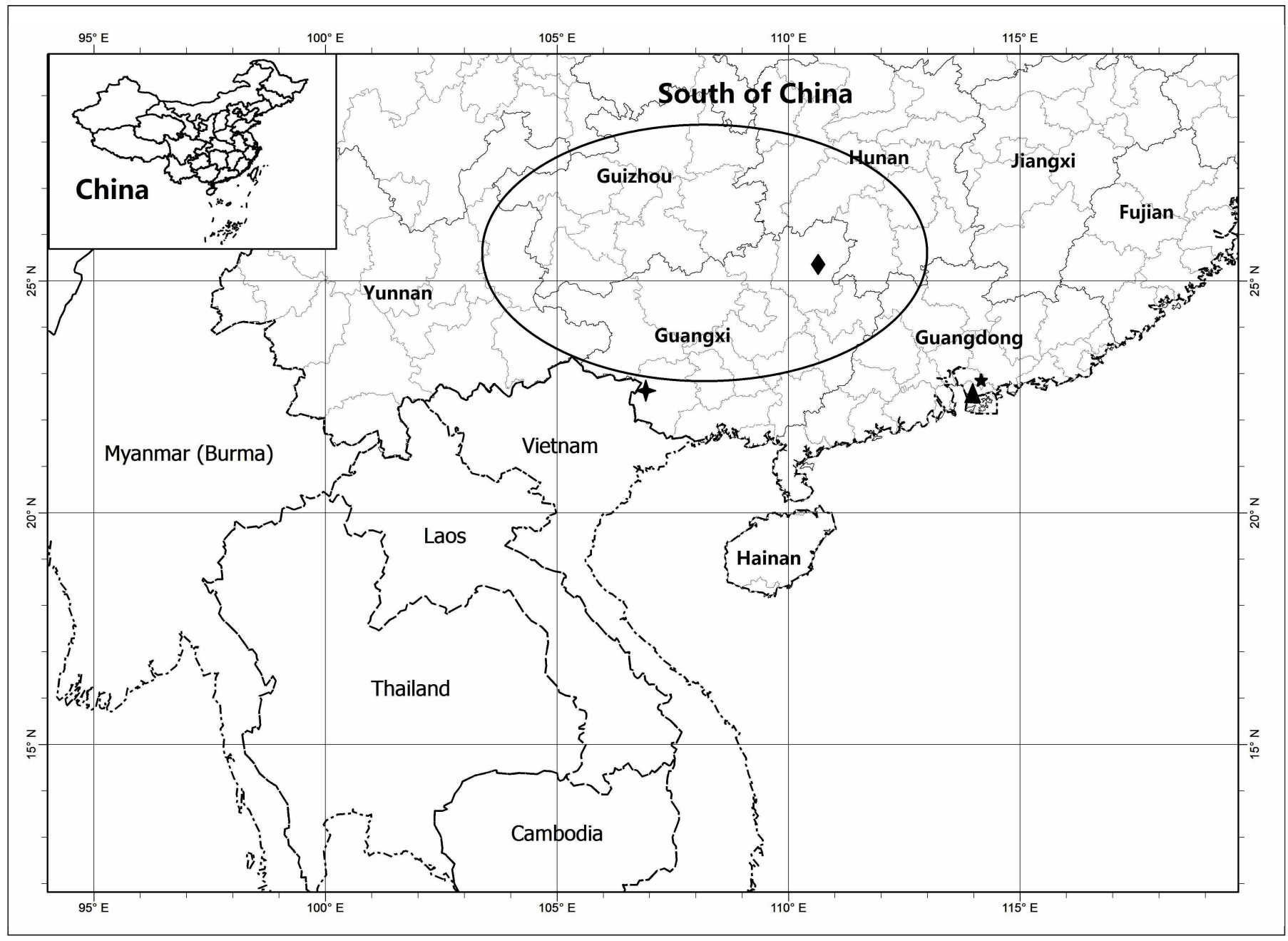

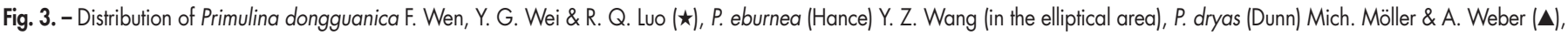
P. napoensis (Z. Y. Li) Mich. Möller \& A. Weber $(\$)$ and P. spec. nov. $(\downarrow)$ in China.

Distribution and habitat. - Primulina dongguanica only grows on a mountainside in the Yinpingzui nature reserve, Guangdong (Dongguan) of China (Fig. 3), at an altitude of $276 \mathrm{~m}$. All plants are growing in damp and dark crevices of granite cliffs near a stream.

Conservation. - The only known population is located near a road, and human activities can potentially jeopardize the existence of this species. In WEI \& al. (2010), we had assigned the IUCN Category EN B2b (ii, iii, iv). Recently, in November 2012, we revisited the type locality again, and found to our surprise the site destroyed due to road building work. Less than 50 individuals only survived. According to IUCN red list categories (IUCN, 2001: 16-18; PULLIN, 2004), we therefore appraised $P$. dongguanica as Critically Endangered, CR B2ab (i, iii, v) + C2a (ii)
Morphological relationships. - Primulina dongguanica F. Wen, Y. G. Wei \& R. Q. Luo is morphologically similar to P. eburnea (Hance) Y. Z. Wang (Fig. 4), P. dryas (Dunn) Mich. Möller \& A. Weber (Fig. 5A-D), P. napoensis (Z. Y. Li) Mich. Möller \& A. Weber (Fig. 5E-H) and P. spec. nov. (Fig. 6), but differs from above-mentioned species in bract morphology and position, calyx lobes shape, filament and pistil length and indumentum, and flowering time (Table 1).

Differences between the new species and its morphologically related species are shown in the following identification key:

1. Bracts large, positioned at a ca. 180-degree angle for the inflorescence

1a. Bracts stretched not at ca. 180-degree angle for the inflorescence 


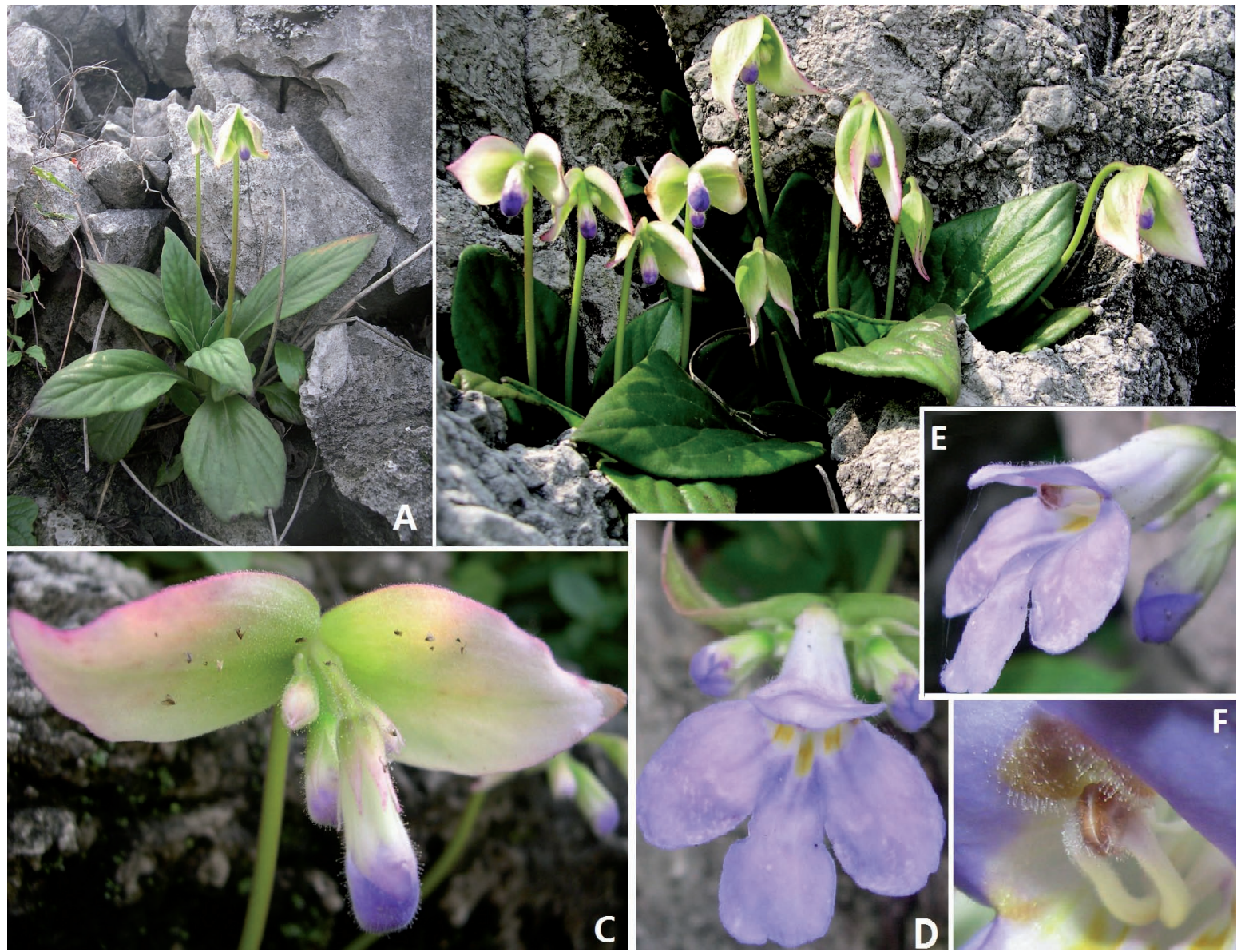

Fig. 4. - Primulina eburnea (Hance) Y. Z. Wang. A. Plant in natural habitat; B. Plants with cymes and flower buds; C. Fully extended bracts and flower buds; D. Frontal view of flower; $\mathbf{E}$. Lateral view of flower; $\mathbf{F}$. Anthers and filaments.

[Photos: Fang Wen]

2. Bracts ovate to orbicular-ovate, ca. $45 \times$ ca. $28 \mathrm{~mm}$, margin entire

\section{P. eburnea}

2a. Bracts ovate to lanceolate, $10-40 \times 4-16 \mathrm{~mm}$, margin entire or crenulate to serrulate.

P. dryas

3. Calyx lobes, lanceolate-linear, corolla outer side densely puberulent and glandular puberulent. ... 4

3a. Calyx lobes broadly lanceolate, corolla outer side densely erect-pubescent.

P. dongguanica

4. Corolla ca. $1.4 \mathrm{~cm}$ long, filaments ca. $4 \mathrm{~mm}$ long....

P. napoensis

4a. Corolla 3.5-4.5 cm long, ca. $11 \mathrm{~mm}$ long

P. spec. nov.
Material examined. - Primulina ebunea (Hance) Y. Z. Wang. China. Chongqing: Daya Xionggou, Huangjiaba, Pengshui County, 900 m, 27.V.1959, Xishi 03146 (PE); Caizhuba, Jinfoshan, Nanchuan County, 1500 m, 28.VI.1978, Plant \& Geography Expedition 136 (PE); Jinfoshan, Nanchuan County, 1200 m, 5.VI.1935, G. L. Qu 1148 (PE); Haokou, Wulong County, 760 m, 21.IV.2008, Z. Y. Liu 182421 (PE); Hubei : Nanping, Badong County, ca. 1000 m, 21.VI.1939, T. P. Wang 11055 (PE); Yaogou, Xinhua, Shennongjia, 27.VI.1967, E Shennong plant Expedition 20433 (HIB); Nanjing Cave, Boyang, Lichuan, 18.V.1973, 11210 (HIB); Hunan: Niufen, Huilong, Xinning County, 280 m, 16.VIII.1985, Y. B. Luo 3143 (PE); Diaoyukeng, Mangshan, Yizhang County, 600 m, 7.IX.2005, B. Z. Xiao 4700, 4687 (PE); Mangshan, Yizhang County, 1.IV.1913, B. Q. Zhong 700 (PE); Guangdong: Shiukwaan, 40 m, 7.IX.1921, F. A. McChure 7042 (PE); Yangmei District, Yangshan County, 120 m, 26.X.1985, Liangguang Team 0391 (PE); Dinghushan, Zhaoqing, 1.III.1980, R. B. He 002, 003, 009, 014, 026, 031 (HENU); Guizhou: Guankou, Qinglong, Dejiang County, 900 m, 22.V.2003, M. T. An 3767 (PE); Tsing-long, 


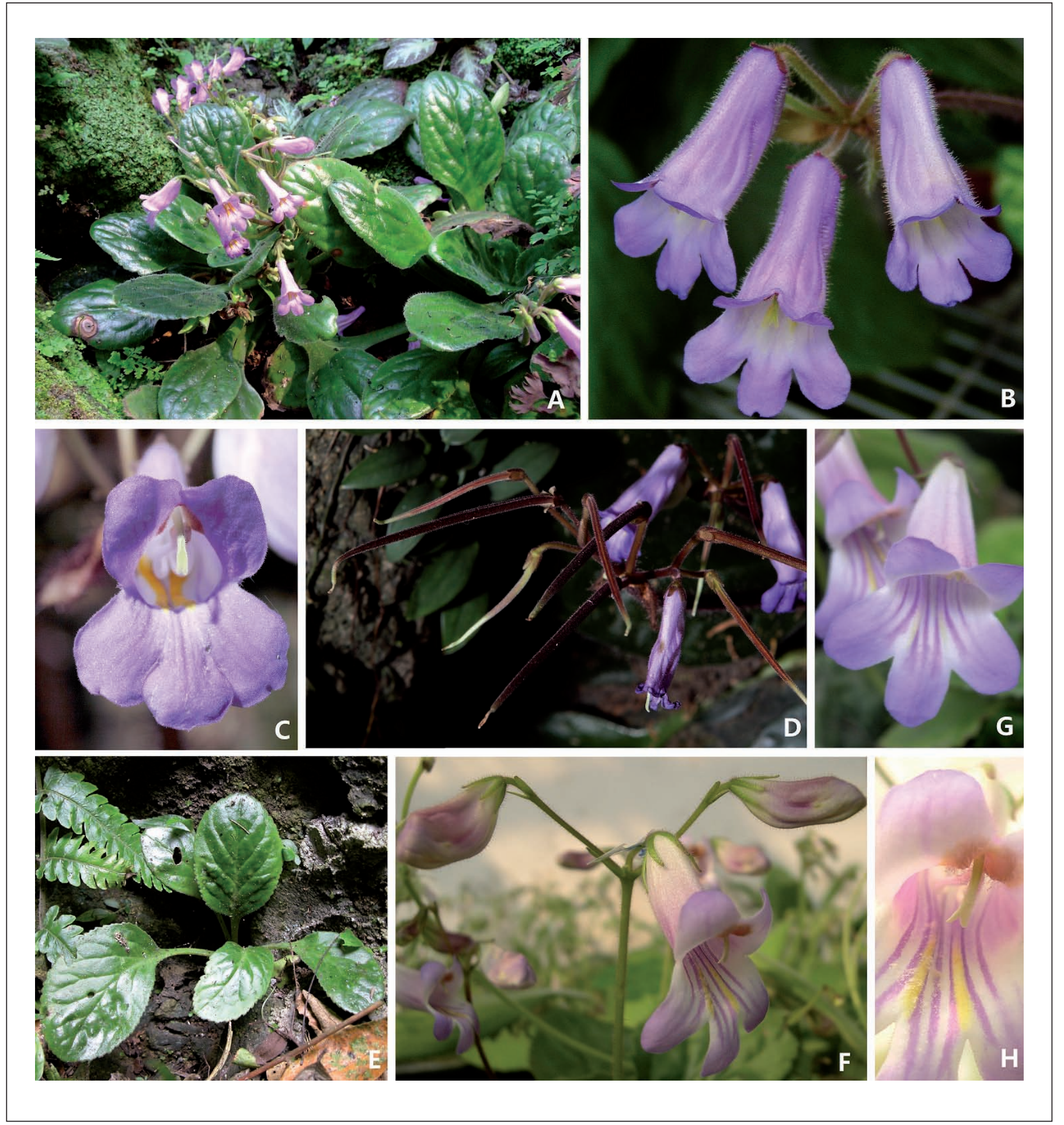

Fig. 5. - Primulina dryas (Dunn) Mich. Möller \& A. Weber and P. napoensis (Z. Y. Li) Mich. Möller \& A. Weber. A-D: P. dryas. A. Habit; B. Cyme; C. Frontal view of flower and stigma; D. Capsule. E-H: P. napoensis. E. Habit; F. Cyme; G. Frontal view of flower; H. Stigma.

[Photos: A-B, D-H: Fang Wen; C: Peter Man] 


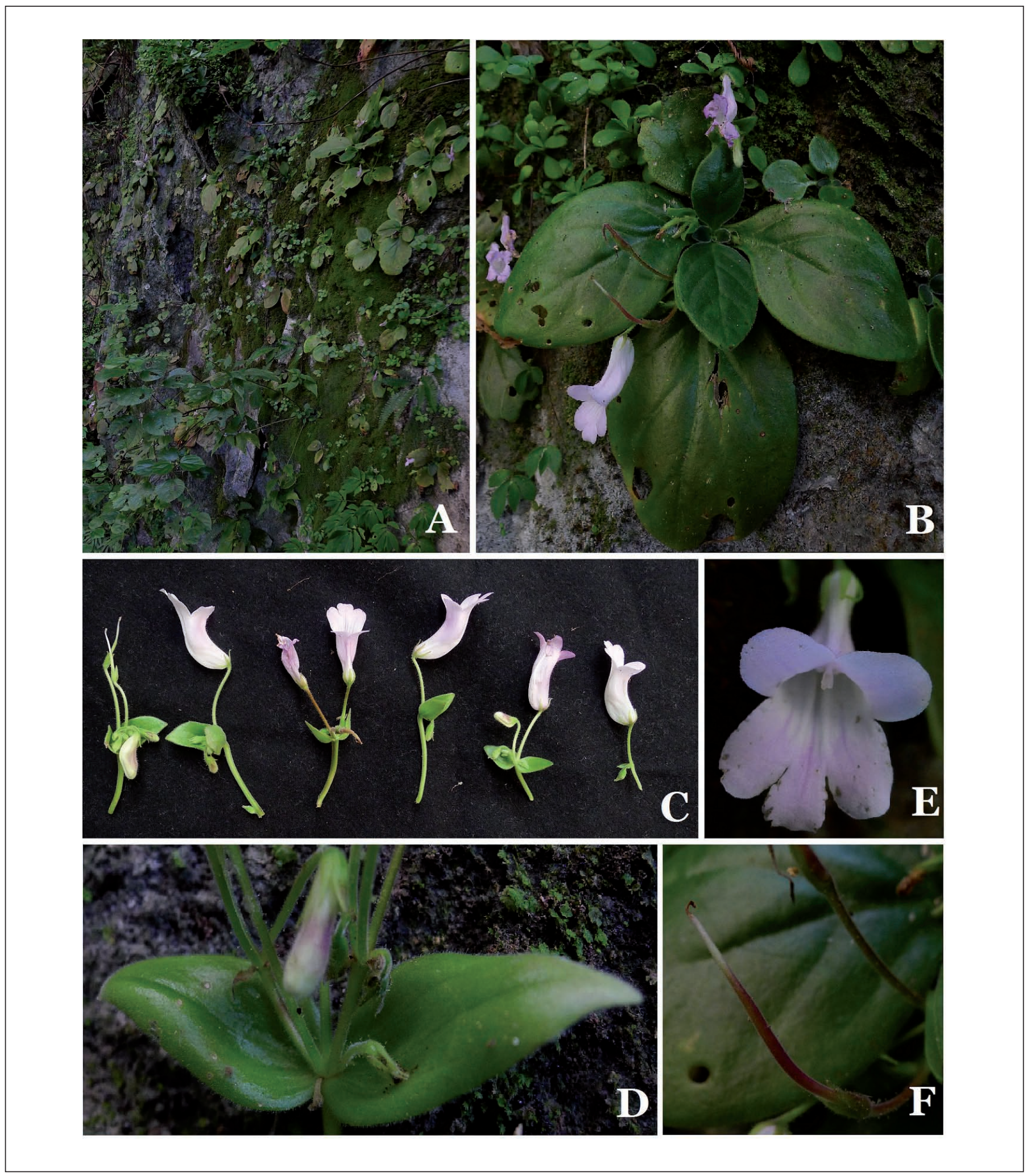

Fig. 6. - Primulina spec. nov. A. Plant in natural habitat; B. Plants with cymes and flower; C. Cymes and lateral view of flowers; D. Bracts; E. Frontal view of flower; F. Capsules.

[Photos: Jian Li, Fang Wen and Xin Hong] 


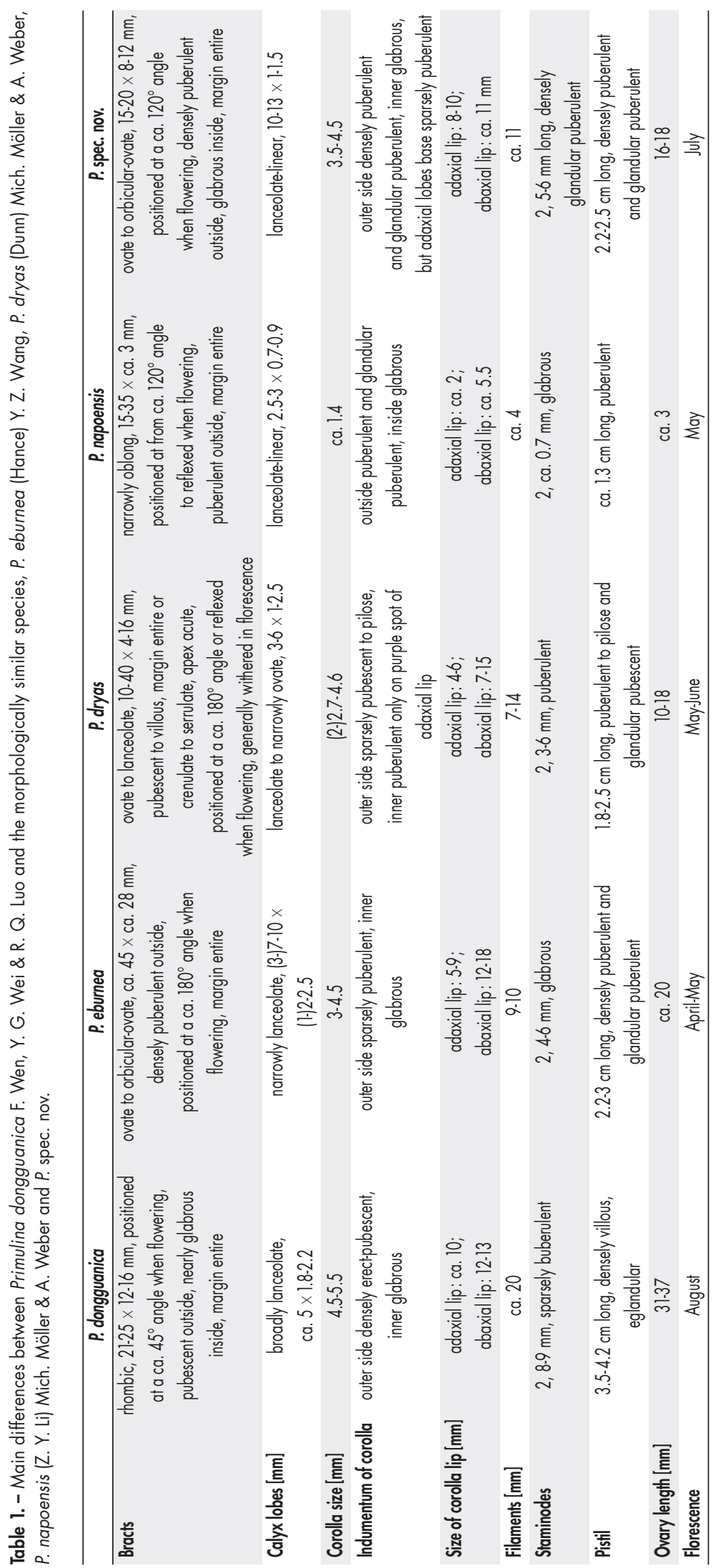


San Tsingchen, 30.V.1936, S. W. Teng 94003 (IBK); Fangzhushan, Xilin Garden, Yanshan, Lingui County, 28.V.1958, H. F. Qin 701007 (HITBC); Dongjia, Luodian County, 6.V.1991, Dian-Qian-Gui Flora Expedition 40236 (KUN); Hechi, 1.VI.1957, Y. K. Li P01489 (WUK); Guangxi : limestone hills, Siqian, 19.VI.1953, Guangxi Team 2692 (PE); Zhenhe, Lingui County, 19.V.1952, C. F. Liang 30323 (IBK); Yanshan botanical garden, Lingui County, 9.IV.1956, S. Q. Zhong A60267 (IBK); Shida, Nonggang, 12.X.1979, Nonggang Expidition 11066 (IBK); Jiangxi : Xiazhuang, Yongfeng County, 7.VI.1982, J. L. Wang \& S. C. Zhang 82181 (LBG); Fanzhichang, Changpo, Nanfeng County, 1.IV.1965, X. X. Yang etc. 650232 (WUK); Sichuan: Zhoujia, Xingwen County, 880 m, 17.V.1959, Chuanjingzhi 0495 (PE); Zhoujia, Xingwen County, 1.V.1951, Ecological Plant Expedition of Sichuan 0495 (CDBI); Huangni, Fenshui, Xuyong County, 1.V.1959, Chuanjinglu 979 (CDBI); Yunnan: Tropical Botanic Garden, Menglun, Mengla County, Xishuangbanna, 21.IV.2003, S. S. Zhou 802 (HITBC); Bajiao Jing, Badahe, Luoping County, 25.XI.1984, Y. D. Yu, C. X. You \& H. Sun 564 (KUN); Zhejiang: Yuhuangshan, Hangzhou, 50 m, 1.VII.1978, C. Z. Zhu s.n. (PE).

P. napoensis (Z. Y. Li) Mich. Möller \& A. Weber. ChinA. Guangxi prov.: Longhua, Napo County, 600 m, 12.V.1989, Exped. Hongshuihe Inst. Bot. Austro-Sin Acad. Sin. 689 (PE, IBSC).

P. dryas (Dunn) Mich. Möller \& A. Weber. CHINA. Hainan Prov.: Qicha, Guangba, Dongfang, 27.XI.1956, S. Q. Chen 11428, 11410 (KUN); Hongkong: Pine Groove, Taipo, 2.VIII.1970, S. Y. Hu 10825 (PE); Ng Tung Chai, N.T., 1.VIII.1973, K. Y. Chan 1154 (PE); Xinjie, 17.XII.1935, H. Y. Chun 11124 (IBK); no detailed locality name, 19.VIII.1933, H. Y. Chun 11124 (IBK); Lianhuashan, 2.X.1930, N. J. Chun 41821 (IBK); Guangdong: Sanhoutian, Shenzhen, 320 m, 30.III.1997, Shenzhen Expedition 66 (PE); Maoming, 13.VIII.1929, Y. Jiang 2952 (IBK); Heishiding, Fengkai County, 1.XI.1980, G. Q. Ding \& L. Yu 6272 (CDBI); Guangxi: Tongluoshan, Cangwu County, 400 m, 24.VII.1956, S. Q. Chun 10076 (IBK); Yuchongweidi, Jinxiu County, 10.XI.1958, Y. C. Chen 1144 (IBK); Guizhou: Gouting, Luodian County, 13.IV.1959, Qiannan Expedition 775 (KUN).

P. spec. nov. China. Guangxi : Baishi, Xingan County, Guilin, 495 m, 1.VII.2010, F. Wen, J. Li \& X. Hong 00177 (IBK; ANU).

\section{Acknowledgments}

The authors are grateful to Prof. Fa-Nan Wei for checking the Latin diagnosis, Mr. Wen-Hong Lin for the drawings, and Mr. Mo Dou, Mr. Wei Guo for the revised French abstract. This study was supported by Science Research Foundation of Guangxi Institute of Botany (Guizhiye 11003), Director Fund project of Guangxi Key Laboratory of Functional Phytochemicals Research and Utilization (ZRJJ2012-9), the Guangxi Natural Science Foundation (2011GXNSFB018050), Science Research Foundation of Guangxi Academy of Sciences (no. 12YJ25ZW013) and West Light Foundation of The Chinese Academy of Sciences.

\section{References}

Don, D. (1822). Descriptions of two new genera of Nepal plants. Edinburgh Philos. J. 7: 82-86.

Hance, H. F. (1883). New Chinese Cyrtandreae. J. Bot. 21: 165-170.

HiLliard, O. M. (2004). A revision of Chirita sect. Liebigia (Gesneriaceae). Edinburgh J. Bot. 60: 361-387.

IUCN (2001). IUCN Red List Categories and Criteria: Version 3.1. IUCN Species Survival Commission. IUCN.

Li, J., Y. Wang, G. J. HuA \& F. Wen (2012). Primulina xiziae sp. nov. (Gesneriaceae) from Zhejiang Province, China. Nordic J. Bot. 30 : 77-81.

LI, J. M. \& M. MöLLER (2009). Chirita grandibracteata (Gesneriaceae), a new species from Yunnan, China. Ann. Bot. Fenn. 46: 125-129.

LI, J. M. \& Y. Z. WANG (2007). Phylogenetic reconstruction among species of Chiritopsis and Chirita sect. Gibbosaccus (Gesneriaceae) based on nrDNA ITS and cpDNA trnL-F sequences. Syst. Bot. 32: 888-898.

LI, Z. Y. \& Y. Z. WANG (2004). Primulina, Chirita and Chiritopsis. In: LI, Z. Y. \& Y. Z. WANG (ed.), Plants of Gesneriaceae in China: 170-282. Henan Sci. \& Technol. Publ. House.

LIU, Y., W. B. XU \& B. PAN (2010). Wentsaiboea tiandengensis sp. nov. and W. luochengensis sp. nov. (Gesneriaceae) from Karst caves in Guangxi, southern China. Nordic J. Bot. 28: 739-745.

Möller, M., A. Forrest, Y. G. Wei \& A. Weber (2011). A molecular phylogenetic assessment of the advanced Asian and Malesian didymocarpoid Gesneriaceae with focus on non-monophyletic and monotypic genera. Pl. Syst. Evol. 292: 223-248.

Möller, M., M. Pfosser, C. G. Jang, V. Mayer, A. Clark, M. L. Hollingsworth, M. H. J. Barfuss, Y. Z. Wang, M. Kiehn \& A. WeBER (2009). A preliminary phylogeny of the 'didymocarpoid Gesneriaceae' based on three molecular data sets: Incongruence with available tribal classifications. Amer. J. Bot. 96: 989-1010

Pullin, A. S. (2004). Conservation biology. Cambridge University Press.

WANG, W. T. (1981). Quinque genera nova Gesneriacearum e Sina. Bull. Bot. Res., Harbin 1:21-28.

WANG, W. T., K. Y. PAN \& Z. Y. Li (1990). Gesneriaceae. In: WANG, W. T. (ed.), Fl. Reipubl. Popularis Sin. 69: 125-181. Science Press.

WANG, W. T., K. Y. PAN \& Z. Y. Li (1998). Gesneriaceae. In: Wu, Z. Y. \& P. H. Raven, (ed.), Fl. China 18. Science Press, Beijing \& Missouri Bot. Garden Press.

Wang, Y. Z., R. B. MaO, Y. Liu, J.M. Li, Y. Dong, Z. Y. Li, \& J. F. Sмiтн (2011). Phylogenetic reconstruction of Chirita and allies (Gesneriaceae) with taxonomic treatments. J. Syst. Evol. 49: $50-64$.

Weber, A., D. J. Middleton, A. Forrest, R. Kiew, C. L. Lim, A. R. Rafidah, S. Sontag, P. Triboun, Y. G. Wei, T. L. Yao \& M. MÖLLER (2011). Molecular systematics and remodelling of Chirita and associated genera (Gesneriaceae). Taxon 60: 767-790. 
Wei, Y. G., F. Wen, M. Möller, A. Monro, Q. Zhang, Q. GAO, H. F. Mou, S. H. Zhong \& C. CuI (2010). Gesneriaceae of South China. Guangxi Sci. \& Technol. Publishing House.

Wen, F., W. L. Li, B. Zhao, G. Y. Liang \& Y. G. Wei (2012a). Primulina purpurea F. Wen, B. Zhao \& Y .G. Wei (Gesneriaceae), a new species from China. Bangladesh J. Pl. Taxon. 19: 167-172.

Wen, F., G. L. Qin, Y. G. Wei, G. Y. Liang \& B. GaO (2012b). Primulina hochiensis var. rosulata (Gesneriaceae) - A new variety at an entrance of a limestone cave from Guangxi, China. Phytotaxa 54: 37-42.

Wen, F., F. WANG \& Y. G. Wei (2012c). Primulina yangshuoensis, a new species of Gesneriaceae from Guangxi, China. Taiwania 57: 55-61.

Wen, F., S. L. XI, Y. WAng, M. S. XIANG \& L. F. Fu (2012d) Primulina fengshanensis (Gesneriaceae), a new species from Guangxi, China. Ann. Bot. Fenn. 49: 103-106.

Wood, D. (1974). A revision of Chirita (Gesneriaceae). Notes Roy. Bot. Gard. Edinburgh. 33: 123-205. 